\title{
Experimental Researches on the Depollution of Wastewater by Forced Oxygenation and Ozonation
}

\author{
EDGAR MORARU ${ }^{1 *}$, OCTAVIAN DONTU ${ }^{1}$, NICOLAE BARAN ${ }^{1}$, ALEXANDRU PETRE ${ }^{2}$, \\ IOANA CORINA MOGA ${ }^{3}$ \\ ${ }^{1}$ University Politehnica of Bucharest, Faculty of Mechanical Engineering and Mechatronics, Department of Mechatronics \\ and Precision Mechanics, 313 Indpendentei Spl., 060042, Bucharest, Romania \\ ${ }^{2}$ University of Medicine and Pharmacy "Carol Davila", Faculty of Dental Medicine, 17-23 Plevnei Road, 020021, Bucharest, \\ Romania \\ ${ }^{3}$ DFR Systems SRL, 46 Drumul Taberei Str., 061392, Bucharest, Romania
}

\begin{abstract}
The paper analyses two experimental variants regarding the treatment of wastewater for depollution by aeration, oxygenation and forced ozonation. The hydrodynamic conditions and the initial data are the same for the two aeration variants. The research was realized with the help of a modern laboratory installation and it was followed the duration in which the value of the initial concentration of dissolved oxygen in water reaches the saturation point. It has been found that when the aeration was performed using a mixture of air and ozone, the duration is reduced by half, but at the same time the method is much more expensive. Also, an innovative technical solution has been presented for the anticlogging of the micro-orifices of the used aeration diffusers.
\end{abstract}

Keywords: depollution systems for wastewater, ozonation of wastewater, fine air bubble generator.

\section{Introduction}

Wastewater aeration aims at creating aerobic conditions for biological processes by saturating a liquid with oxygen. This cleaning method is considered the most environmentally friendly, therefore aeration stations are often called the most modern and safe systems that are used for wastewater treatment [1-9]. The main purpose of wastewater aeration is to increase or maintain an optimal level of dissolved oxygen in a polluted water mass. Water aeration involves the transfer of oxygen from atmospheric air to water, which is, in fact, a phenomenon of transfer of a gas into a liquid. The most common method of removing organic impurities under the action of an aerobic bacterial biomass is to introduce oxygen into the wastewater. Oxygen comes most commonly from atmospheric air, in this case the process bearing the name of water aeration. Water temperature is an important factor, so the warmer the water, the lower the concentration of dissolved oxygen e.g., in clean water, the concentration of dissolved oxygen is $11.3 \mathrm{mg} / \mathrm{dm}^{3}$ at $10^{\circ} \mathrm{C}$ and only $8.3 \mathrm{mg} / \mathrm{dm}^{3}$ at $25^{\circ} \mathrm{C} \mathrm{[7].}$

On the other side, ozone is a molecule containing three oxygen atoms. Ozone is a very active form of oxygen that is formed under conditions where oxygen comes into contact with a very high energy field. Under these conditions oxygen atoms react with each other forming ozone $\left(\mathrm{O}_{3}\right)$. It is chemically unstable and has a reversible reaction which causes the ozone molecule to break down into oxygen. It is environmentally friendly and does not leave any chemical residue. It represents the most powerful oxidant, because of it the viruses and bacteria being destroyed structurally. It has the property that due to the third oxygen atom it is highly reactive. Basically, this oxygen atom is attached to the molecules of contaminating viruses and bacteria, with which they come into contact. Another feature of ozone is that it is highly soluble. At $25^{\circ} \mathrm{C}$ the solubility of ozone is $109 \mathrm{mg} / \mathrm{dm}^{3}$, while the solubility of oxygen is only $8 \mathrm{mg} / \mathrm{dm}^{3}$.

Therefore, the efficiency of purification of industrial wastewater is improved by the use of ozone, due to the cleaning and disinfection properties. Ozone has a very strong bactericidal and viricidal effect, with fast action, even instantaneous, in the $p \mathrm{H}$ range of $5.6-9.8$ at temperatures of $0-37^{\circ} \mathrm{C}$.

*email: eddy_milan91@yahoo.com 
Apart from its disinfectant properties, ozone acts on a large number of pollutants. The oxidation power of ozone allows the destruction of organic substances $[10,11]$.

\section{Materials and methods}

In conception, design and execution of the experimental installation, the purpose was to determine experimentally the variation of the dissolved oxygen concentration in water as a function of time for the wastewater treatment. The purpose of these experimental researches was to validate the functioning of a fine bubble generator (FBG) realized with the help of modern $\mathrm{CNC}$ machining installation using either air or a mixture of air and ozone by reaching the saturation point of dissolved oxygen in water in a due time. From previous researches [12-15], the concentration of dissolved oxygen in water tends towards saturation concentration after $2 \mathrm{~h}$. So, the measurement of oxygen concentration will be done from 15 in $15 \mathrm{~min}$.

The wastewater treatment researches were carried out in a laboratory of the University Politehnica of Bucharest, where a modern experimental installation for the ecological treatment of wastewater (Figure 1) was developed.

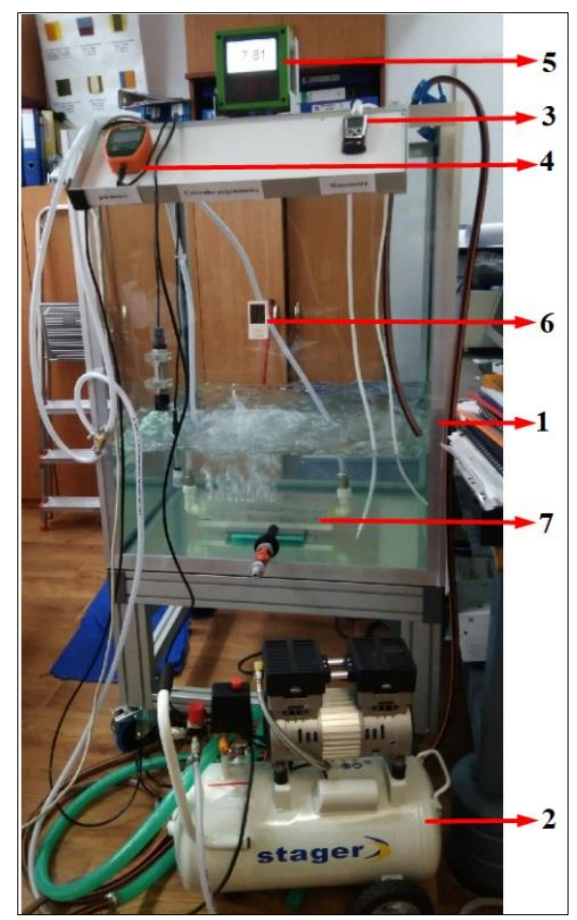

Figure 1. Experimental installation for the ecological wastewater treatment: (1) water tank;

(2) compressed air tank; (3) manometer; (4) $\mathrm{pH}$-meter; (5) mechatronic system consisting of oxygen sensor and controller; (6) thermometer; (7) fine bubble generator (FBG)

The water tank was made of high-performance Saint Gobain glass with a total of 5 plates. The thickness of the glass was selected by $12 \mathrm{~mm}$ and the dimensions of the executed water tank were $800 \times 800 \times 1000 \mathrm{~mm}$ with a total volume of $640 \mathrm{~L}$. The test basin was also provided with a mobile support / stand on wheels. An aluminium alloy was chosen as a material for the strength structure. A support for the assembly of the measuring, control and visualization instruments was also developed. This installation has the advantage of compactness and some performance measurement and control systems. 


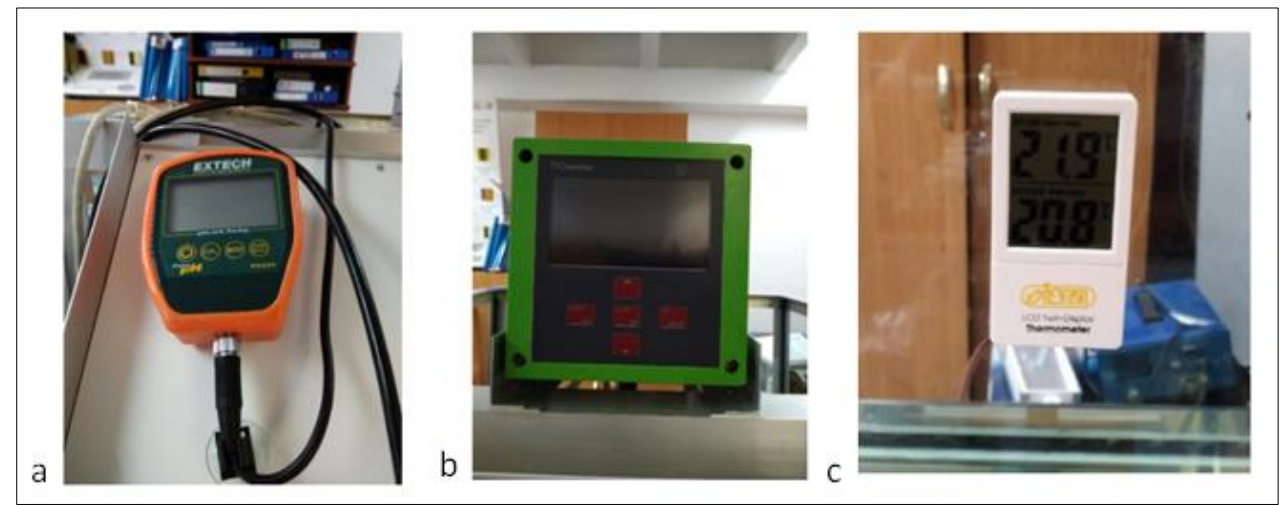

Figure 2. Measurement and control systems: (a) pH-meter;

(b) oxygenometer controller; (c) thermometer

For the purpose of water aeration in the presented installation, several FBG with micro-orifices with diameters between 0.1 and $0.9 \mathrm{~mm}$ were tested. It is known that smaller diameters will make the wastewater aeration process more efficient and increase the process of aeration of wastewater [15].

These plates were mounted on a plastic cassette. Previous studies have shown the efficiency and viability of using additive technologies for the realization of cassettes in Figure $3[16,17]$. In this study were used cassettes executed by conventional subtractive technologies.

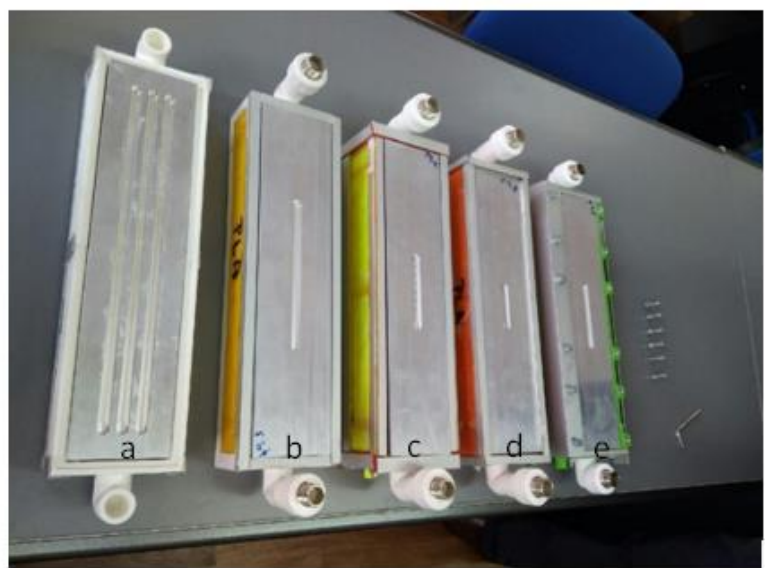

Figure 3. Plates with micro-orifices with different diameters mounted on cassettes realized by additive technologies [18-21]:

(a) $\phi=0.1 \mathrm{~mm}$; (b) $\phi=0.3 \mathrm{~mm}$; (c) $\phi=0.7 \mathrm{~mm}$; (d) $\phi=0.9 \mathrm{~mm} ;(\mathrm{e}) \phi=0.5 \mathrm{~mm}$

\section{Results and discussions}

In conception and design of the experimental installation, it was started from research purpose and namely the experimental determination of the variation of dissolved oxygen concentration in water as a function of time. The purpose of the experimental measurements was to determine the time when the amount of oxygen dissolved in water reached the saturation. Figure 4 shows the concentration of oxygen dissolved in water as a function of time for the $0.5 \mathrm{~mm}$ micro-orifices diffuser. The initial dates were: $\mathrm{t}_{\text {water }}=21.4^{\circ} \mathrm{C}, \mathrm{p}_{\text {air }}=600 \mathrm{~mm} \mathrm{H}_{2} \mathrm{O}, \mathrm{C}_{0}=3.13 \mathrm{mg} / \mathrm{dm}^{3}, \mathrm{Q}=0,6 \mathrm{~m}^{3} / \mathrm{h}$. In about $2 \mathrm{~h}$ the level of oxygen dissolved in water reached the saturation concentration, i.e., about $8.9 \mathrm{mg} / \mathrm{dm}^{3}$. Research has also focused on the use of ozone, to see how the concentration of dissolved oxygen increased using the atmospheric air-ozone mixture. It was found that by introducing this gas mixture, the period when the saturation concentration was reached was almost halved. 


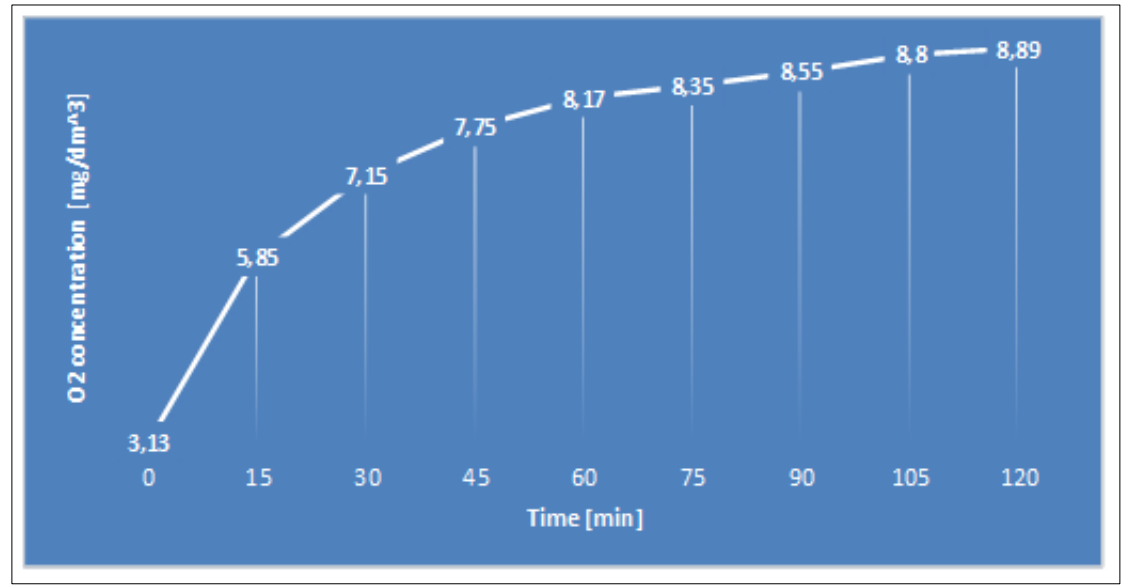

Figure 4. Dissolved oxygen concentration as a function of time by introducing air through the $0.5 \mathrm{~mm}$ micro-orifices diffusers

In other words, to reach the saturation concentration in the same hydrodynamic regime, the operating time for the variant with the use of ozone is twice shorter, but much more expensive. In the field of wastewater treatment, it is known that the smaller the air bubbles diameter, the higher the oxygen transfer rate. This has been demonstrated experimentally [3, 7-10]. Experiments have shown that in the case of $0.1 \mathrm{~mm}$ micro-orifices plate, the oxygen reached the saturation concentration in the shortest time.

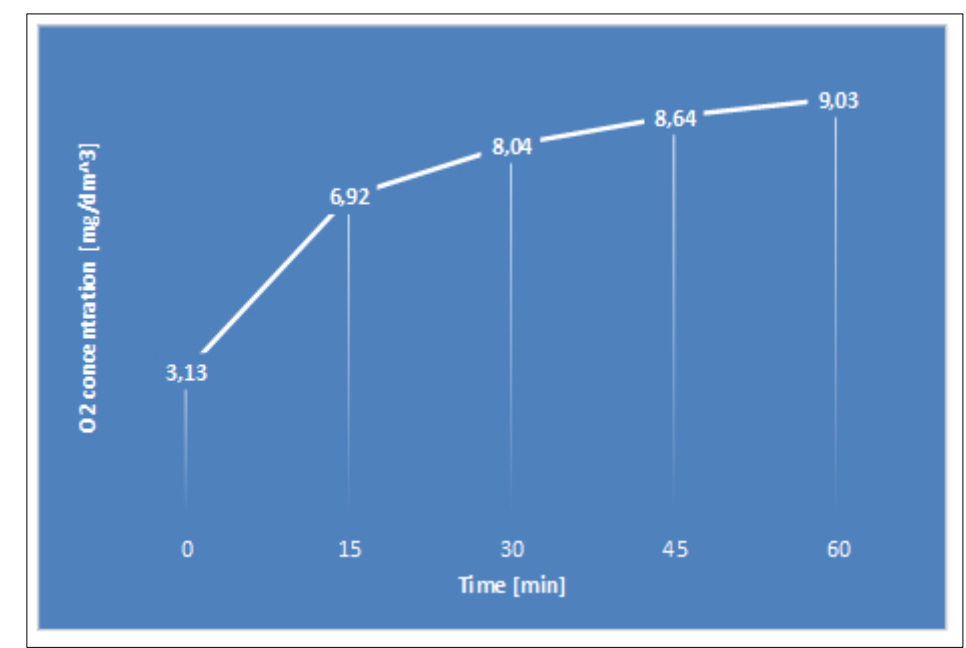

Figure 5. Dissolved oxygen concentration as a function of time by introducing air-ozone mixture through the $0.5 \mathrm{~mm}$ micro-orifices diffusers

Figure 5 presents the dissolved oxygen concentration as function of time by introduction air-ozone mixture through the $0.5 \mathrm{~mm}$ micro-orifices diffusers and it is observed that the value of oxygen concentration at saturation is reached in a shorter time than in the case of variant I. Figure 6 presents the oxygenation curve for the plates with micro-orifices of $0.1 \mathrm{~mm}\left(\right.$ at $\mathrm{t}_{\mathrm{water}}=24{ }^{\circ} \mathrm{C}$ ). 


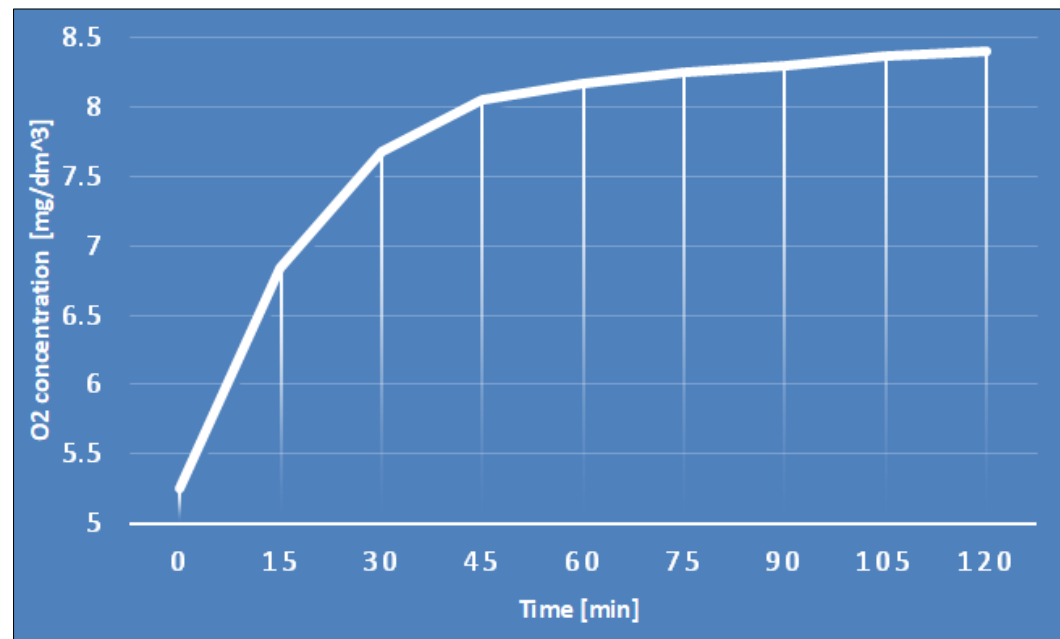

Figure 6. Dissolved oxygen concentration as a function of time by introducing air through the $0.1 \mathrm{~mm}$ micro-orifices diffusers

Figure 7 (graph from the Figure 4) and Figure 8 show the testing of FBG in the developed installation and a viable method for increasing the dissolved oxygen in water with minimal energy consumption and low costs has been demonstrated experimentally, especially in the case of using atmospheric air.

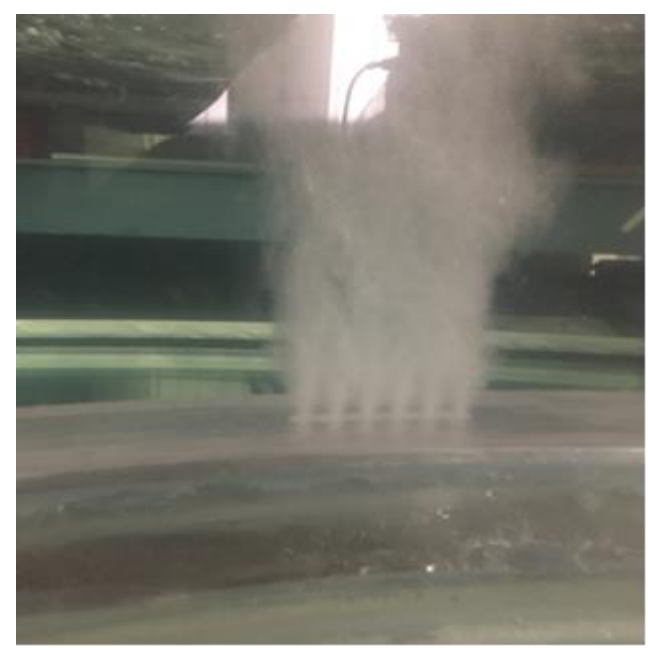

Figure 7. Overview of FBG with $\phi=0.5 \mathrm{~mm}$ during operation

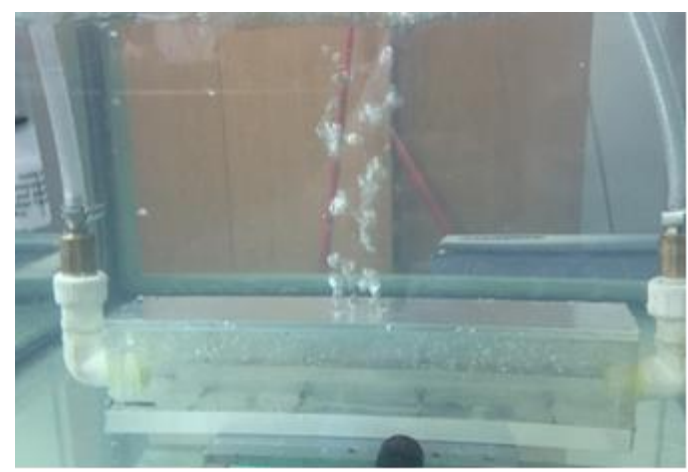

Figure 8. Overview of FBG with $\phi=0.9 \mathrm{~mm}$ 
Aeration systems with micro-orifices for increasing the dissolved oxygen concentration in wastewater often face problems caused by the residual components in the basin, which in time obstruct the micro-holes. For an efficient operation of the system, the micro-orifices must be permanently cleaned in order to carry out their task. However, in the event of prolonged operation or if the aeration system is switched off, these orifices may become clogged and may cause serious problems of the system operation.

The authors propose a technical solution to solve this problem of micro-orifices clogging which consist in coupling of the micro-orifices plate with an ultrasonic transducer, generating phenomena of ultrasonic cavitation. The concept is based on the generation of ultrasonic waves at high frequencies (approx. 37-40 kHz), for a short time. The ultrasonic concentrator is rigidly fixed to the plate with orifices, using a resin with adherent properties, and inserted into a flange tube which performs the sealing. A 3D representation of the complete system is shown in Figure 9, as well as a section through the system.

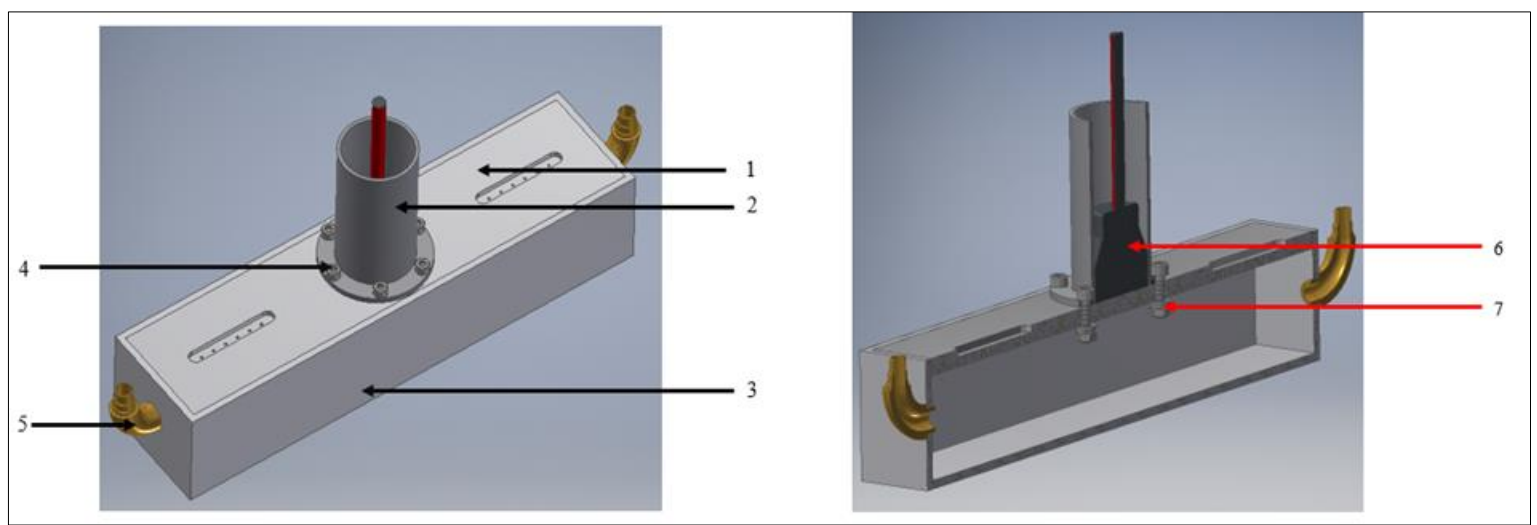

Figure 9. 3D representation of the aeration system with ultrasonic transducer [18]:

(1)micro-orifice plate, (2) flange tube, (3) cassette, (4) screw, (5) connection, (6) ultrasonic transducer, (7) nut

The system consists of the micro-orifice plate (1) which is fixed by means of a silicone layer on the cassette (3) in which the connection (5) is attached, one for each end. The flange tube (2) is fixed by means of screws (4) to the plate (1). This tube has on the lower surface of the flange a channel for an Oring sealing element. Inside the tube is inserted the ultrasonic transducer (6) which will be glued to the plate. Starting from the effects produced by ultrasounds with a certain frequency and preset values of the amplitude of the ultrasonic vibrations in the presence of water, the phenomenon of ultrasonic cavitation will be developed, which will favor the unclogging of the micro-orifices [22].

\section{Conclusions}

For the same initial data, it is observed that the gas mixture (air + ozone) it is twice as efficient as the method of introducing atmospheric air. In other words, to get from an initial concentration of dissolved oxygen $\left(\mathrm{C}_{0}\right)$ to saturation concentration $\left(\mathrm{C}_{\mathrm{s}}\right)$ in the same hydrodynamic regime, the operating time for variant II (mixture of air and ozone) is twice as short. To obtain shortening of the time from $\mathrm{C}_{0}$ to $\mathrm{C}_{\mathrm{s}}$, the variant II will be used, i.e., a mixture of air and ozone gas, but the costs will be higher. The diameter of the micro-orifices of the used diffusers significantly influences the time at which the oxygen reaches saturation, the wastewater treatment being in this case more efficient, and this has been demonstrated experimentally. The main advantage of the proposed ultrasonic mechatronic system for cleaning the micro-holes of the diffusers used to treat wastewater is the fact that the plates of the fine bubble generators can be monitored online and when the sensors detect the clogging of the holes, the mechatronic system automatically starts the ultrasound emission and the ultrasonic cavitation process of micro-holes cleaning is started. 
Acknowledgments: This work was supported by a grant of the Romanian National Authority for Scientific Research and Innovation, CCCDI - UEFISCDI, project number COFUND-MANUNET IIICEBIOTREAT, within PNCDI III and by a grant of the Romanian Ministry of Education and Research, CCDI - UEFISCDI, project number PN-III-P2-2.1-PTE-2019-0628, within PNCDI III.

\section{References}

1. ISBASOIU, E.C., Treaty of fluid mechanics (in Romanian), AGIR, Bucharest, Romania, 2011.

2. WHITE, F.M., Fluid mechanics, McGraw Hill inc, ISBN 9780077422417, New York, 2011.

3. KUZMAN, R., Thermodynamic properties of water and steam, tables and diagrams (in Romanian), Technical Publishing, Bucharest, Romania, 1967.

4. STEFANESCU, M., NECHIFOR G., PATROESCU, I.V., DINU, L.R., IONESCU, I.A., DAMIAN C., Modern Biogas Generation Method Based on Ultrasonic and Anaerobic Fermentation of Municipal Wastewater Biological Sludge, Rev.Chim., 70(12), 2019, 4591-4595.

5. STEFANESCU, M., DINU, L.R., BUMBAC C., Ultrasonic Alkaline Pretreatment of Biological Activated Sludge from Wastewater Treatment Plants, Rev. Chim., 70(1), 2019, 301-303.

6. CARBUREANU, M., BAIESU, A.S., The Development of a Neuro-Fuzzy Expert System for

Wastewater Treatment Processes Monitoring, Rev.Chim., 69(1), 2018, 179-186.

7. ROBESCU, D.L., STROE, A., PRESURA, D., ROBESCU, D., Wastewater treatment techniques (in Romanian), Technical Publishing, Bucharest, Romania, 2011.

8. STENSTROM, M.K., ROSSO, D., Aeration, University of California, Los Angeles, 2010.

9. HAND, D.W., HOKANSON, D.R., CRITTENDEN, J.C., MWH's Water Treatment: Principles and Design, Third Edition, chapter 4- Air stipping and aeration, John Wiley \& Sons, Inc, 2012.

10. STENSTORM, M.K., LEU, S-Y., JIANG, P., Theory to Practice: Oxygen Transfer and the New ASCE Standard, Water Environment Foundation, 2006.

11. OPRINA, G., PINCOVSCHI, I., BARAN G., Hydro-gas dynamics of aeration systems equipped with bubble generators (in Romanian), Politehnica Press Publishing, Bucharest, Romania, 2009.

12. TANASE, E.B., The influence of the composition of the gas blown in water on the dissolved oxygen concentration (in Romanian), PhD Thesis, University Politehnica of Bucharest, 2017.

13. CALUSARU, I., The influence of the physical properties of the liquid on the efficiency of the oxygenation processes (in Romanian), PhD Thesis, University Politehnica of Bucharest, 2014.

14. MATEESCU, G.M., Hidro-gas dynamics of fine bubble generators, PhD Thesis, University Politehnica of Bucharest, 2011.

15. BARAN, N., CONSTANTIN, M., TANASE, B., MORARU, E., MOGA, C.I., Influence of Fine Bubble Generator on Time Variation of Dissolved Oxygen Concentration in Water, Rev.Chim., 70(6), 2019, 2132-2135.

16. BESNEA, D., GHEORGHE, G.I., DONTU, O., MORARU, E., CONSTANTIN, V., MOGA, I.C., Experimental researches regarding realization of wastewater treatment elements by means of modern technologies, International Journal of Mechatronics and Applied Mechanics, 4, 2018, 61-65.

17. MORARU, E., BESNEA, D., DONTU, O., GHEORGHE G.I., MOGA I.C., POPESCU G.E., In: Gheorghe G. (eds) Proceedings of the International Conference of Mechatronics and CyberMixMechatronics - 2019. ICOMECYME 2019. Lecture Notes in Networks and Systems, vol 85. Springer, Cham.

18. SLATINEANU, L., DODUN, O., NAGIT, G., COTEATA, M., BOSOANCA, G., BESLIU, I., Fine Details Obtained by 3D Printing and Using Polymers, Mater.Plast., 55(4), 2018, 474-477.

19. BUCURESTEANU, A., PRODAN D., MOTOMANCEA A., Execution of Plastic Parts Using 3D Scanners and 3D Printers, Mater. Plast., 55(2), 2018, 215-218.

20. BESNEA, D., DINU, E., MORARU, E., SPANU, A., RIZESCU, C., CONSTANTIN, V., Experimental Researches Regarding the Manufacturing of New Thermoplastic Materials Used in Additive Technologies, Mater. Plast., 55(1), 2019, 167-170. 
21. PRISECARU, D.A., BESNEA, D., MORARU, E., CANANAU, S., Additive Manufactured Bioplastics for Conceptual Models of Knee Customized Prostheses, Mater. Plast., 55(4), 2019, 957-963. 22. DONTU, O., BESNEA, D., MORARU E., Ultrasonic mechatronic system for unclogging diffuser micro-orifices for wastewater treatment (in Romanian), 2018, Patent request A/01057/05.12.2018.

$\overline{\text { Manuscript received: } 19.02 .2020}$ 